\title{
Antifungal Activity of Paenibacillus kribbensis Strain T-9 Isolated from Soils against Several Plant Pathogenic Fungi
}

\author{
Sheng Jun $\mathrm{Xu}^{1}$, Sae Jin Hong ${ }^{1}$, Woobong $\mathrm{Choi}^{2}$ and Byung Sup Kim ${ }^{1 *}$ \\ ${ }^{1}$ Department of Plant Science, Gangneung-Wonju National University, Gangneung 210-702, Korea \\ ${ }^{2}$ Department of Biotechnology and Bioengineering, Dongeui University, Busan 614-714, Korea
}

(Received on June 14, 2013; Revised on October 1, 2013; Accepted on October 13, 2013)

The bacterial strain T-9, which shows strong antifungal activity, is isolated from the soils of Samcheok, Gangwondo and identified as Paenibacillus kribbensis according to morphological and taxonomic characteristics and 16S rRNA gene sequence analysis. The $P$. kribbensis strain T-9 strongly inhibits the growth of various phytopathogenic fungi including Botrytis cinerea, Colletotricum acutatum, Fusarium oxysporum f. sp. radicis-lycopersici, Magnaporthe oryzae, Phytophthora capsici, Rhizoctonia solani, and Sclerotium cepivorum in vitro. Also, the $P$. kribbensis strain T-9 exhibited similar or better control effects to plant diseases than in fungicide treatment through in vivo assays. In the 2-year greenhouse experiments, $P$. kribbensis strain T-9 was highly effective against clubroot. In the 2-year field trials, the $P$. kribbensis strain T-9 was less effective than the fungicide, but reduced clubroot on Chinese cabbage when compared to the control. The abovedescribed results indicate that the strain T-9 may have the potential as an antagonist to control various phytopathogenic fungi.

Keywords : antifungal ability, in vivo assay, Paenibacillus kribbensis, plant pathogenic fungi, 16S rRNA gene

Recently, the use of synthetic fertilizers and pesticides have resulted in deterioration of soil structure and increase in soil-borne phytopathogens (Bailey and Lazarovits, 2003). As a result, along with many phytopathogenic fungi such as $B$. cinerea, $F$. oxysporum, $P$. capsici, $R$. solani, and $S$. cepivorum etc. having a wide range of host plants, it has been very difficult to control the spread of the plant disease. Although applying fungicide has been one of

*Corresponding author.

Phone) +82-33-640-2353, FAX) +82-33-640-2909

E-mail) bskim@gwnu.ac.kr the conventional methods for controlling fungal diseases, there is increasing international concern over the use of fungicides on crops because of their harmful effects on human health and the emergence of pathogen resistance to fungicides. To cope with this problem, various disease managements including biological control, have been applied.

Biological control by microorganisms (Huang et al., 2012; Kim et al., 2012; Li et al., 2012) has received considerable attention as a reliable substitute for the use of various hazardous chemical fungicides, which have raised serious concerns of food and environmental contamination (Fernando et al., 2005). Microorganisms also play an essential role in several life support functions as they enable soil to recycle nutrients, suppress plant pathogens (Mendes et al., 2011), and serve as a suitable substrate for plant growth (Kim et al., 2011). Among the myriads of bacteria in the plant rhizosphere, a few spore-forming plant growth promoting rhizobacteria (PGPR) attract special attention due to their stable habitancy in soil (Emmert and Handelsman, 1999; Jin et al., 2006).

Soil samples were collected from the Chinese cabbage, garlic, and paddy fields in 30 regions of Samcheok, Gangwon province, South Korea during November 2011. Each sample was air-dried at ambient temperature and then passed through an $850 \mu \mathrm{m}$ mesh sieve to remove plant debris. Soil samples were preserved in polyethylene bags at room temperature before use. Soil suspensions were prepared in sterile water and cultured on the surface of potato dextrose agar medium (PDA, Difco, USA) and tryptic soy agar medium (TSA, Difco, USA). The plates were incubated at $25^{\circ} \mathrm{C}$ for 10 days. Afterwards, colonies with different morphological appearances were chosen from the countable plates and streaked on fresh similar medium to obtain pure cultures.

Bacterium was identified by morphological and taxonomic characterization and 16S rRNA gene sequencing assay. Morphological characteristics were examined on 

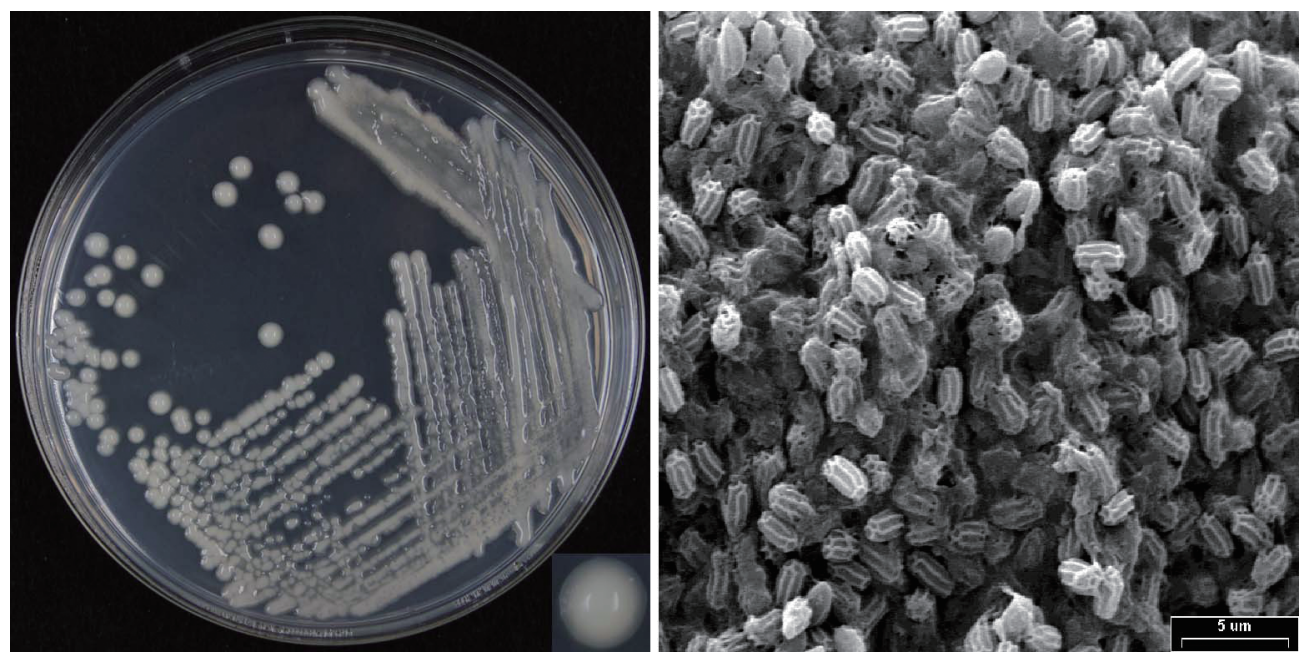

Fig. 1. Colony shape on PDA medium and spore morphological characteristics by SEM of strain T-9. Bar size indicates $5 \mu$ m.

an SEM at an accelerating voltage of $10 \mathrm{kV}$. Taxonomic characterization of the strain was performed on the basis of test for oxidase, catalase, $\mathrm{H}_{2} \mathrm{~S}$ production, gelatin hydrolysis, starch hydrolysis, nitrate reduction, urase hydrolysis, casein digestion, arginine dihydrolase, ornithine decarboxylase, esculin hydrolysis and utilization of carbon such as glucose, sucrose, dulcitol, salicin, D-mannitol, D-adonitol, L-arabinose, D-xylose, and D-trehalose (Takagi et al., 1993). The results of these tests were scored as either positive or negative.

The total genomic DNA was extracted as described by Nishiguchi et al. (2002). The 16S rRNA gene was amplified by polymerase chain reaction using universal primers 27F and 1492R (Bioneer, Korea). The amplified DNA was purified using a gel purification kit (Bioneer, Korea) and was sequenced at Bioneer. Similarity searches of the sequence obtained was performed using the BLAST function of GenBank.

The predominant strain obtained from soil samples of Samcheok was named as T-9 and found to be a Gramvariable, rod-shaped, and facultative anaerobic bacterium. It produced flat colonies and unsmooth-surfaced spores (Fig. 1) and catalase (Table 1) although it did not produce $\mathrm{H}_{2} \mathrm{~S}$. Methyl red reaction was positive while Voges-Proskauer reaction was negative. An array of carbon sources were utilized like glucose, lactose, sucrose, salicin, L-arabinose, raffinose, maltose, and cellobiose, but not dulcitol, D-adonitol, myo-inositol, and L-rhamnose. The $16 \mathrm{~S}$ rRNA gene sequence analysis indicated that the closest relative (99\%) of the strain T-9 (1465 bp) was P. kribbensis AM49 (AF391123) (Fig. 2). The 16S rRNA gene sequence of strain T-9 was deposited in the GenBank database with an accession number KF019740. From the results of morphologic and biological characteristics, and $16 \mathrm{~S}$ rRNA gene sequence analysis, the predominant strain T-9 obtained from soil samples was identified as $P$. kribbensis and thus named P. kribbensis strain T-9.

The genus Paenibacillus, originally included within the Bacillus and reclassified as a separate genus (Ash et al., 1993), is prevalently distributed in different soils and plant rhizospheres (Berge et al., 2002; von der Weid et al., 2002; Garbeva et al., 2003; Yoon et al., 2003). Different species of Paenibacillus have been demonstrated as having potential antifungal activities (Fortes et al., 2008; He et al., 2007; Liu et al., 2008; Raza et al. 2008; von der Weid et al., 2003; von der Weid et al., 2005). The P. kribbensis is recently described as a new Paenibacillus species isolated from soil (Yoon et al., 2003). Some strains produced antimicrobial substances, suggesting an important role in the soil. However, no biological role of this species in the rhizosphere have been reported.

The antifungal activity of $P$. kribbensis strain T-9 against the phytopathogenic fungi was performed by dual culture. Briefly, a mycelial column (6.5 $\mathrm{mm}$ in diameter) was cut off from the white perimeter portion of the colony, which had been cultured on PDA plates at $25^{\circ} \mathrm{C}$ for 7 days, and placed at a distance $1.5 \mathrm{~cm}$ away from the rim of a fresh PDA plate. Afterwards, the P. kribbensis strain T-9 growing in PDA was sowed in a hole with a sterilized toothpick on the PDA plate $(1.5 \mathrm{~cm}$ away from the other rim). Simultaneously, control plates inoculated in different mycelial columns were prepared without $P$. kribbensis strain T-9. The antagonistic effect of the control plates was evaluated by measuring the size of the inhibition zone on the PDA plates following culturing at $25^{\circ} \mathrm{C}$ for 14 days.

The $P$. kribbensis strain T-9 showed strong antagonistic 
Table 1. Differential characteristics of antagonistic strain T-9 and Paenibacillus kribbensis

\begin{tabular}{|c|c|c|}
\hline Characteristic & Strain T-9 & P. kribbensis ${ }^{\mathrm{a}}$ \\
\hline Cell shape & rod & rod \\
\hline Cell size $(\mu \mathrm{m})$ & $1.3-1.7 \times 4.2-6.8$ & $1.3-1.8 \times 4.0-7.0$ \\
\hline Oxygen requirement & $\begin{array}{l}\text { facultative } \\
\text { anaerobic }\end{array}$ & $\begin{array}{l}\text { facultative } \\
\text { anaerobic }\end{array}$ \\
\hline Endospore formation & $+^{\mathrm{b}}$ & + \\
\hline Gram stain & $+/-$ & $+/-$ \\
\hline Nitrate reduction & + & + \\
\hline Gelatin hydrolysis & + & + \\
\hline Starch hydrolysis & + & + \\
\hline Urea hydrolysis & - & - \\
\hline Casein hydrolysis & + & + \\
\hline Oxidase & - & - \\
\hline \multicolumn{3}{|l|}{$\begin{array}{l}\text { Sole carbon and energy } \\
\text { sources: }\end{array}$} \\
\hline L-Arabinose & + & + \\
\hline D-Cellobiose & + & + \\
\hline D-Glucose & + & + \\
\hline Lactose & + & + \\
\hline D-Mannose & + & + \\
\hline Melibiose & + & + \\
\hline D-Raffinose & + & + \\
\hline D-Sorbitol & - & - \\
\hline L-Rhamnose & - & + \\
\hline D-Xylose & + & + \\
\hline D-Trehalose & + & + \\
\hline D-Mannitol & + & + \\
\hline Adonitol & - & - \\
\hline Maltose & + & + \\
\hline Sucrose & + & + \\
\hline
\end{tabular}

${ }^{\mathrm{a}}$ Data for P. kribbensis are from Yoon et al. (2003).

${ }^{\mathrm{b}}+$, Positive; -, Negative; +/-, Gram-variable.

activity against a wide range of phytopathogenic fungi that cause disease on different crops (Table 2). It produced the highest antifungal activity against $P$. capsici, which was cosmopolitan in distribution. Furthermore, there was a moderate antifungal activity against $B$. cinerea, $C$. acutatum and $M$. oryzae. Other test phytopathogenic fungi were also inhibited, but the antifungal activity was relatively less.

The in vivo efficiency of P. kribbensis strain T-9 for control of anthracnose in pepper fruits, Phytophthora blight in pepper plant, blast, sheath blight in rice plant and gray mold in tomato plant, was evaluated in plastic sieve systems or under greenhouse conditions (Table 3). Pepper (Capsicum annuum) cv. Super manitta and Hongjinjoo, rice (Oryza sativa) cv. Nakdongbyeo and tomato (Solanum lycopersicum) cv. Super dotaerang were sown in horticultural soil in seedling plate. The plants were kept in the greenhouse for one month. To obtain culture broth, P. kribbensis strain T-9 was cultured in potato dextrose broth medium (PDB, Difco, USA) for three days, which included incubation in a rotary shaker at $200 \mathrm{rpm}$ and $25^{\circ} \mathrm{C}$. After incubation, P. kribbensis strain T-9 suspension was diluted in distilled water to $10^{8} \mathrm{cfu} / \mathrm{ml}\left(\mathrm{OD}_{620}=0.1\right)$. Each seedling and fruit was treated with growth broth one day before inoculation with $B$. cinerea, $C$. acutatum, $M$. oryzae, $P$. capsici, and $R$. solani. For pepper anthracnose, each fruit was soaked in culture broth, water, or propineb for $30 \mathrm{~min}$. For pepper Phytophthora blight, each seedling was dip-treated with culture broth, water, or dimethomorph for $10 \mathrm{~min}$. Also culture broth, water, or fungicides were sprayed on each seedling for other plant diseases. Chemical fungicides were used as the positive control and water was used as the negative control. The inoculated plants were placed in a moist chamber to maintain approximately $90 \%$ humidity at $25^{\circ} \mathrm{C}$ for $24 \mathrm{~h}$, and then transferred to the growth room for further incubation. There were three replicates for each treatment.

The P. kribbensis strain T-9 for control of Phytophthora blight in pepper plant, blast, sheath blight in rice plant and gray mold in tomato plant, was highly effective, reducing disease severity by $92.9 \%, 78.5 \%, 100 \%$, and $89.8 \%$ relative to the inoculated control, respectively. The chemical fungicides were used as reference, which reduced disease severity by $99.3 \%, 74.3 \%, 100 \%$ and $93.2 \%$, respectively. The in vivo efficacy of $P$. kribbensis strain T-9 against anthracnose in pepper fruits was evaluated in plastic sieve systems. The $P$. kribbensis strain T-9 was highly effective, which showed a control efficiency of $96.7 \%$. The synthetic fungicide was used as reference, which showed a $92.3 \%$ control value.

The suppressive effects of $P$. kribbensis strain T-9 against Plasmodiophora brassicae in the greenhouse and the field were assessed in 2011 and 2012, respectively (Fig. 3). Chinese cabbage (Brassica campestris) cv. Gaeulmas, a highly susceptible to clubroot, was sown in horticultural soil in seedling plate. The plants were kept in the greenhouse for one month. To obtain culture broth, the method was same in upper. Frozen galls were soaked in distilled water for a while to soften the tissue, and then they were macerated in a homogenizer with distilled water at high speed. For inoculation, inoculate suspension was mixed 


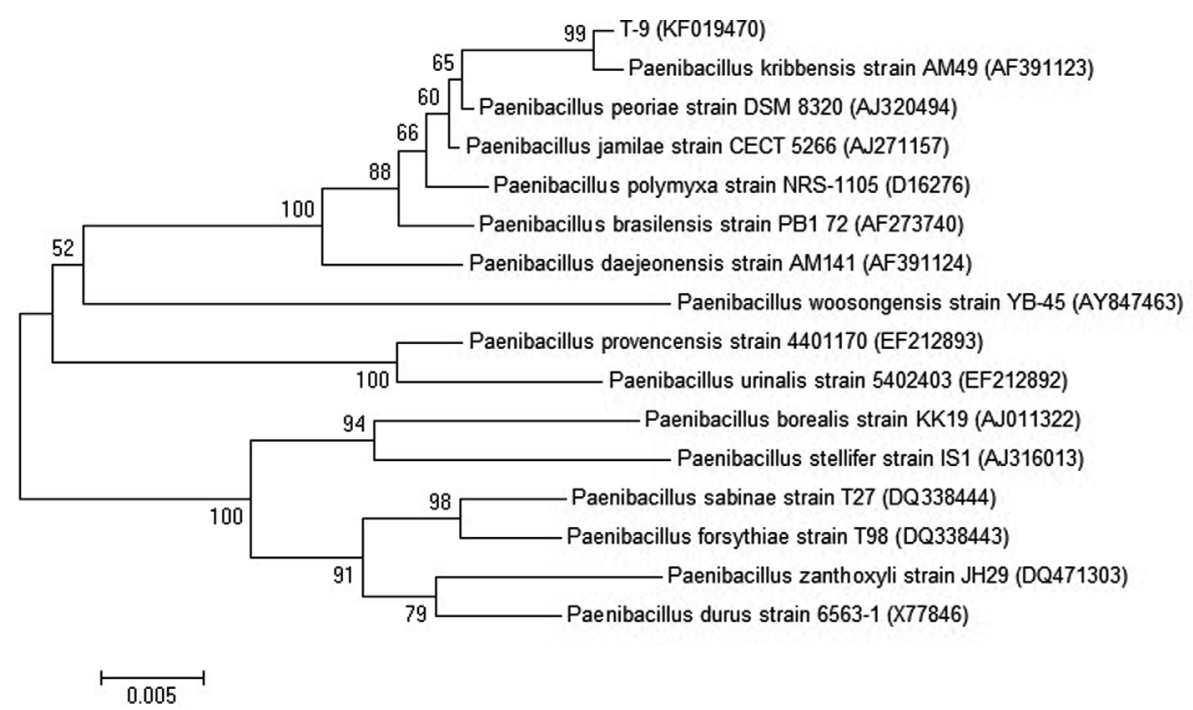

Fig. 2. Phylogenetic relationship between strain T-9 and representative species based on partial 16S rRNA gene sequence developed with the ClustalW program in MEGA 5.10 and constructed using the Neighbor-joining method with 1,000 bootstrap replicates. The values indicate the percentage of clustering matches. The scale bar indicates the number of differences in base composition among sequences.

Table 2. Antagonistic activity of strain T-9 against various phytopathogenic fungi in dual culture assay

\begin{tabular}{lcc}
\hline \multicolumn{1}{c}{ Pathogen } & KACC accession No. ${ }^{\text {a }}$ & ${\text { Inhibition zone }(\mathrm{mm})^{\mathrm{b}}}^{\text {Botrytis cinerea }}$ \\
Colletotrichum acutatum & KACC 40574 & $12.09 \pm 1.74$ \\
Fusarium oxysporum f. sp. radicis-lycopersici & KACC 43123 & $12.05 \pm 0.63$ \\
Magnaporthe oryzae & KACC 40031 & $5.61 \pm 0.63$ \\
Phytophthora capsici & KACC 40441 & $11.78 \pm 0.61$ \\
Rhizoctonia solani (Chinese cabbage bottom rot) & KACC 40483 & $19.04 \pm 2.71$ \\
Rhizoctonia solani (Rice sheath blight) & KACC 40113 & $8.00 \pm 0.29$ \\
Sclerotium cepivorum & KACC 40103 & $6.48 \pm 0.30$ \\
\hline
\end{tabular}

${ }^{a}$ KACC: Korean Agricultural Culture Collection.

${ }^{b}$ Values are mean \pm SD of three independent observations.

into horticultural soil. In 2011 and 2012, Chinese cabbage was transplanted in a plastic pot containing the clubrootinfested horticultural soil. Each seedling was dipped into culture broth. Cyazofamid was used as the positive control and water as the negative control. The seedlings were watered regularly to keep constant soil moisture during cultivation in the greenhouse. After forty days, each root was rinsed with tap water and assessed for clubroot severity based on a $0-4$ scale, where 0 indicated no infection; 1 indicated $1-25 \%$ of roots infected; 2 indicated $26-50 \%$ of roots infected; 3 indicated $51-75 \%$ of roots infected; and 4 indicated more than $75 \%$ of roots infected. Statistical analyses were conducted with the Statistical Analysis System for personal computers (Ver. 9.2, SAS Institute Inc.). Fisher's protected least significant difference
(LSD) at $P \leq 0.05$ was applied to determine whether or not differences between treatments were significant.

In 2011 and 2012, a study using Chinese cabbage was conducted to assess the efficacy of microbes in the field, based on the efficacy observed in a previous experiment. Inoculate suspension was mixed into field soil using a rotary cultivator. Each seedling was dipped in culture broth for $10 \mathrm{~min}$. Seedlings were transplanted in the infected field and cyazofamid was used as the positive control and water as the negative control. The trials were arranged in a randomized complete block design with three replicates. The seedlings were watered regularly to keep constant soil moisture. After seventy days, each root was rinsed with tap water and assessed for clubroot severity based on the $0-4$ scale mentioned above. 
Table 3. The control effect of the strain T-9 against several plant pathogenic fungi in susceptible host plants

\begin{tabular}{|c|c|c|c|}
\hline Plant diseases $^{\mathrm{a}}$ & Treatments $^{\mathrm{b}}$ & $\begin{array}{c}\text { Disease severity }(\%) \text { or disease spot } \\
\text { extended length }(\mathrm{mm})^{c}\end{array}$ & Control value $(\%)$ \\
\hline \multirow[t]{3}{*}{ Pepper anthracnose } & Strain T-9 & $2.3 \pm 1.8 \mathrm{~b}^{\mathrm{d}}$ & $96.7 \pm 1.8 \mathrm{~A}$ \\
\hline & Propineb & $5.3 \pm 2.6 b$ & $92.3 \pm 2.5 \mathrm{~A}$ \\
\hline & Control & $68.3 \pm 22.9 \mathrm{a}$ & - \\
\hline \multirow[t]{3}{*}{ Pepper phytophthora blight } & Strain T-9 & $4.0 \pm 2.7 \mathrm{~b}$ & $92.9 \pm 6.4 \mathrm{~A}$ \\
\hline & Dimethomorph & $0.4 \pm 0.3 b$ & $99.3 \pm 0.6 \mathrm{~A}$ \\
\hline & Control & $56.4 \pm 28.5 \mathrm{a}$ & - \\
\hline \multirow[t]{3}{*}{ Rice blast } & Strain T-9 & $10.8 \pm 3.8 b$ & $78.5 \pm 9.4 \mathrm{~A}$ \\
\hline & Tricyclazole & $13.3 \pm 1.4 \mathrm{~b}$ & $74.3 \pm 4.2 \mathrm{~A}$ \\
\hline & Control & $51.7 \pm 5.2 \mathrm{a}$ & - \\
\hline \multirow[t]{3}{*}{ Rice sheath blight } & Strain T-9 & $0.0 \pm 0.0 \mathrm{~b}$ & $100.0 \pm 0.0 \mathrm{~A}$ \\
\hline & Validamycin A & $0.0 \pm 0.0 \mathrm{~b}$ & $100.0 \pm 0.0 \mathrm{~A}$ \\
\hline & Control & $137.4 \pm 19.5 \mathrm{a}$ & - \\
\hline \multirow[t]{3}{*}{ Tomato gray mold } & Strain T-9 & $6.7 \pm 2.0 \mathrm{~b}$ & $89.8 \pm 2.0 \mathrm{~A}$ \\
\hline & Fludioxonil & $4.6 \pm 3.6 \mathrm{~b}$ & $93.2 \pm 5.1 \mathrm{~A}$ \\
\hline & Control & $65.9 \pm 5.1 \mathrm{a}$ & - \\
\hline
\end{tabular}

${ }^{a}$ Fruits of pepper were inoculated by dropping $20 \mu \mathrm{l}$ of $C$. acutatum conidia suspension (more than $10^{5}$ conidia/ml). Pepper seedlings were inoculated by drenching $20 \mathrm{ml}$ of $P$. capsici zoospores suspension (more than $10^{4}$ sporangia/ml, chilling) near the seedling. Rice seedlings were inoculated by spraying $M$. oryzae spores suspension (more than $10^{5}$ spores $/ \mathrm{ml}, 1 \%$ Tween 20 ) on foliage. Rice seedlings were inoculated by sticking PDA disk with $R$. solani on stem base. Tomato seedlings were inoculated by spraying $B$. cinerea spores suspension (more than $10^{5}$ spores/ml, PDB) on foliage.

${ }^{\mathrm{b}}$ For pepper anthracnose, each fruit which surface was slightly scratched by a sandpaper was soaked in culture broth, water (control), or propineb for $30 \mathrm{~min}$. For pepper phytophthora blight, each seedling was dip-treated with culture broth, water (control), or dimethomorph for 10 min. Culture broth, water (control), or fungicides were sprayed on each seedling for other plant diseases.

cDisease spot extended length was calculated for rice sheath blight. A disease severity was calculated over all of the plants for the treatment of other plant diseases.

${ }^{\mathrm{d}}$ Means and standard error based on three replicates sharing a common capital letter (control value) or lower case letter (disease severity or disease spot extended length) were not significantly different based on the protected LSD test at $P \leq 0.05$.

For greenhouse experiment, the P. kribbensis strain T-9 was highly effective against clubroot, which showed a control efficiency of $89.3 \%$ and $99.2 \%$ in 2011 and 2012, respectively. Cyazofamid was used as a reference, which showed $86.3 \%$ and $100 \%$ control values. For field trials, $P$. kribbensis strain T-9 had no substantial impact on clubroot severity, with $79.6 \%$ and $82.2 \%$ disease severity on the susceptible cultivar of Chinese cabbage, which reduced the disease severity by $11.7 \%$ and $12.6 \%$ in 2011 and 2012 , respectively. The cyazofamid treatment reduced the disease severity by $24.9 \%$ and $85.8 \%$.

The stratagem of controlling the biological properties of the $P$. brassicae has become an important approach for creating a long-lasting effect on the facilitation of sustainable agriculture; however, only a few antagonistic microorganisms have been reported, including Micromonospora rosea subsp. rosea and Streptomyces spp. (Kim et al., 2004; Lee et al., 2008; Wang et al., 2012), Streptoverticillium olivoreticuli ssp. (Kim et al., 2002), Cellulosimicrobium cellulans, and Paenibacillus spp. (Choi et al., 2007). The progress and applicable fields of biological control for clubroot are limited compared to other soil-borne plant diseases, and there are no commercial biological control products available. The continuous search for antagonistic agents against clubroot is necessary. In this study, the suppressive effects of $P$. kribbensis strain T-9 against $P$. brassicae were assessed in the greenhouse and the field in 2011 and 2012. We found the efficacy observed from the field trial to be lower than that of the greenhouse experiment. For the greenhouse experiment, $P$. kribbensis strain T-9 showed a good control efficiency of $89.3 \%$ and $99.2 \%$ in 2011 and 2012, respectively. However, for field trials, there was no substantial impact, but the treatment reduced the clubroot on the susceptible cultivar of Chinese cabbage, with disease severity, by $79.6 \%$ and $82.2 \%$ in 2011 and 2012, respectively. Basic environmental conditions, such 


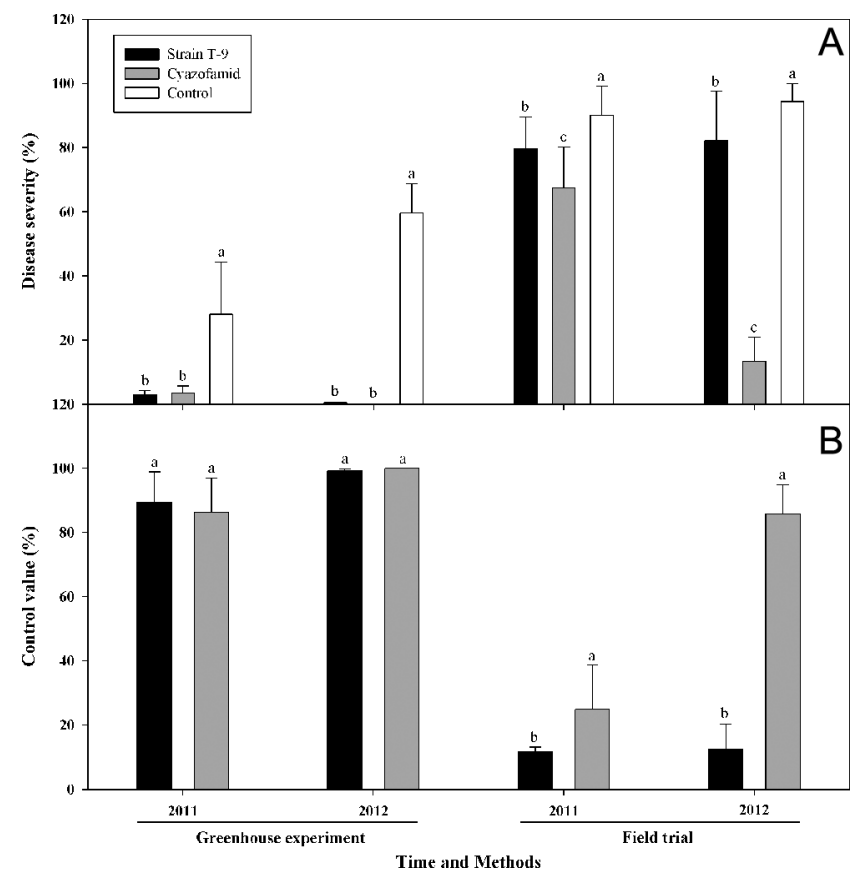

Fig. 3. Disease severity (A) and control value (B) of greenhouse experiment and field trails by strain T-9 and fungicide treatment to control clubroot caused by P. brassicae in 2011 and 2012. Plant roots were dip-treated with culture broth, water (control), or cyazofamid for $10 \mathrm{~min}$. Means and standard error based on three replicates sharing a common letter were not significantly different based on the protected LSD test at $P \leq 0.05$.

as temperature, moisture, and soil physical and chemical characteristics, can greatly affect the interactions among plant, pathogen, and biocontrol agents in various ways, and all of these effects may influence the efficacy of biological control (Larkin and Fravel, 2002). On the other hand, enormous microorganisms exist in the rhizosphere of plants, which may influence the efficacy of biological control. Finally, endospore formation and longer generation times influence them to rapidly colonize roots, which they directly protect against soil-borne pathogens while they adapt their fitness to that of rhizosphere (Ryu et al., 2005).

In summary, this study is the first antagonistic activity assay of $P$. kribbensis strain T-9 against various soil-borne phytopathogenic fungi. It was found that the $P$. kribbensis strain T-9 has the potential to offer protection to plants against different soil-borne phytopathogenic fungi, in addition to its antagonistic activity, suggesting that further studies should be considered for using $P$. kribbensis strain T-9 as a biological control agent and enhancer of control efficiency in field trials.

\section{Acknowledgements}

This study was supported by a grant (Project No. 6090025) from the Screening Center for Disease Resistant Vegetable Crops of TDPAF funded by the MIFAFF of the South Korean government.

\section{References}

Ash, C., Priest, F. G. and Collins, M. D. 1993. Molecular identification of rRNA group 3 bacilli (Ash, Farrow, Wallbanks and Collins) using a PCR probe test. Proposal for the creation of a new genus Paenibacillus. Ant. Van Leeuwen. 64:253-260.

Bailey, K. L. and Lazarovits, G. 2003. Suppressing soil-borne diseases with residue management and organic amendments. Soil Till. Res. 72:169-180.

Berge, O., Guinebretiere, M. H., Achouak, W., Normand, P. and Heulin, T. 2002. Paenibacillus graminis sp. nov. and Paenibacillus odorifer sp. nov., isolated from plant roots, soil and food. Int. J. Syst. Evol. Microbiol. 52:607-616.

Choi, K. H., Yi, Y. S., Lee, S. L., Kang, K. R., Lee, E. J., Hong, S. W., Young, J. M., Park, Y. H., Choi, G. J., Kim, B. J. and Lim, Y. H. 2007. Microorganisms against Plasmodiophora brassicae. J. Microbiol. Biotechnol. 17:873-877.

Emmert, E. A. and Handelsman, J. 1999. Biocontrol of plant disease: a (Gram) positive perspective. FEMS Microbiol. Lett. 171:1-9.

Fernando, W. G. D., Ramarathnam, R., Krishnamoorthy, A. S. and Savchuk, S. C. 2005. Identification and use of potential bacterial organic antifungal volatiles in biocontrol. Soil Biol. Biochem. 37:955-964.

Fortes, T. O., Alviano, D. S. and Tupinambá, G. 2008. Production of an antimicrobial substance against Cryptococcus neoformans by Paenibacillus brasilensis $\mathrm{Sa} 3$ isolated from the rhizosphere of Kalanchoe brasoloensis. Microbiol. Res. 163:200-207.

Garbeva, P., van Veen, J. A. and van Elsas, J. D. 2003. Predominant Bacillus spp. in agricultural soil under different management regimes detected via PCR-DGGE. Microb. Ecol. 45:302-316.

He, Z. G., Kisla, D., Zhang, L. W., Yuan, C. H., Green-Church, K. B. and Yousef, A. E. 2007. Isolation and identification of a Paenibacillus polymyxa strain that coproduces a novel lantibiotic and polymyxin. Appl. Environ. Microbiol. 73:168178.

Huang, X. Q., Zhang, N., Yong, X. Y., Yang, X. M. and Shen, Q. R. 2012. Biocontrol of Rhizoctonia solani damping-off disease in cucumber with Bacillus pmilus SQR-N43. Microbiol. Res. 167:135-143.

Jin, R. D., Han, T. H., Kim, Y. W. and Kim, K. Y. 2006. Suppression of clubroot formation in Chinese cabbage by the chitin compost and broth. Agric. Chem. Biotechnol. 49:171-175.

Kim, B. J., Choi, G. J., Cho, K. Y., Yang, H. J., Shin, C. S., Lee, 
C. H. and Lim, Y. H. 2002. Antifungal activities against Plasmodiophora brassicae causing club root. J. Microbiol. Biotechnol. 12:1022-1025.

Kim, H. S., Sang, M. K., Jung, H. W., Jeun, Y. C., Myung, I. S. and Kim, K. D. 2012. Identification and characterization of Chryseobacterium wanjuense strain KJ9C8 as a biocontrol agent of Phytophthora blight of pepper. Crop Prot. 32:129137.

Kim, S. H., Shin, C. S., Moon, S. G., Yi, Y. S., Choi, G. J., Cho, K. Y., Song, J. Y. and Lim, Y. H. 2004. Isolation and characterization of Streptomyces sp. KACC 91027 against Plasmodiophora brassicae. J. Microbiol. Biotechnol. 14:220-223.

Kim, W. I., Won, K. C., Kim, S. N., Chu, H. S., Ryu, K. Y., Yun, J. C. and Park, C. S. 2011. Genetic diversity of cultivable plant growth-promoting rhizobacteria in Korea. J. Microbiol. Biotechnol. 21:777-790.

Larkin, R. P. and Fravel, D. R. 2002. Effect of varying environmental conditions on biological control of Fusarium wilt of tomato by nonpathogenic Fusarium spp. Phytopathology 92:11601166.

Lee, S. O., Choi, G. J., Choi, Y. H., Jang, K. S., Park, D. J., Kim, C. J. and Kim, J. C. 2008. Isolation and characterization of endophytic actinomycetes from Chinese cabbage roots as antagonists to Plasmodiophora brassicae. J. Microbiol. Biotechnol. 18:1741-1746.

Li, Q. L., Ning, P., Zheng, L., Huang, J. B., Li, G. Q. and Hsiang, T. 2012. Effects of volatile substances of Streptomyces globisporus JK-1 on control of Botrytis cinerea on tomato fruit. Biol. Control 61:113-120.

Liu, W. W., Mu, W., Zhu, B. Y., Du, Y. C. and Liu, F. 2008. Antagonistic activities of volatiles from four strains of Bacillus spp. and Paenibacillus spp. against soil-borne plant pathogens. Agric. Sci. China 7:1104-1114.

Mendes, R., Kruijt, M., de Bruijn, I., Dekkers, E., van der Voort, M., Schneider, J. H. M., Piceno, Y. M., DeSantis, T. Z., Andersen, G. L., Bakker, P. A. H. M. and Raaijmakers, J. M. 2011. Deciphering the rhizosphere microbiome frome for disease-suppressive bacteria. Science 332:1097-1100.

Nishiguchi, M. K., Doukakis, P., Egan, M., Kizirian, D., Phillips,
A., Prendini, L., Rosenbaum, H. C., Torres, E., Wyner, Y., DeSalle, R. and Giribet, G. 2002. DNA isolation procedures. In: Methods and Tools in Biosciences and Medicine: Techiques in molecular systematics and evolution, eds. by R. DeSalle, G. Giribet and W. Wheeler, pp. 279-280. Birkhäuser Verlag, Basel, Switzerland.

Raza, W., Yang, W. and Shen, Q. R. 2008. Paenibacillus polymyxa: antibiotics, hydrolytic enzymes and hazard assessment. J. Plant Pathol. 90:419-430.

Ryu, C. M., Kim, J. W., Choi, O. H., Park, S. Y., Park, S. H. and Park, C. S. 2005. Nature of a root-associated Paenibacillus polymyxa from field-grown winter barley in Korea. $J$. Microbiol. Biotechnol. 15:984-991.

Takagi, H., Shida, O., Kadowaki, K., Komagata, K. and Udaka, S. 1993. Characterization of Bacillus brevis with descriptions of Bacillus migulanus sp. nov., Bacillus choshinensis sp. nov., Bacillus parabrevis sp. nov., and Bacillus galactophilus sp. nov. Int. J. Syst. Evol. Microbiol. 43:221-231.

von der Weid, I., Duarte, G. F., van Elsas, J. D. and Seldin, L. 2002. Paenibacillus brasilensis sp. nov., a novel nitrogenfixing species isolated from the maize rhizosphere in Brazil. Int. J. Syst. Evol. Microbiol. 52:2147-2153.

von der Weid, I., Alviano, D. S., Santos, A. L. S., Soares, R. M. A., Alviano, C. S. and Seldin, L. 2003. Antimicrobial activity of Paenibacillus peoriae strains NRRL BD-62 against a broad spectrum of phytopathogenic bacteria and fungi. J. Appl. Microbiol. 95:1143-1151.

von der Weid, I., Artutsson, V., Seldin, L. and Jansson, J. K. 2005. Antifungal and root surface colonization properties of GFPtagged Paenibacillus brasilensis PB177. World J. Microbiol. Biotechnol. 12:1591-1597.

Wang, J., Huang, Y., Lin, S., Liu, F., Song, Q., Peng, Y. L. and Zhao, L. 2012. A strain of Streptomyces griseoruber isolated from rhizospheric soil of Chinese cabbage as antagonist to Plasmodiophora brassicae. Ann. Microbiol. 62:247-253.

Yoon, J. H., Oh, H. M., Yoon, B. D., Kang, K. H. and Park, Y. H. 2003. Paenibacillus kribbensis sp. nov. and Paenibacillus terrae sp. nov., bioflocculants for efficient harvesting of algal cells. Int. J. Syst. Evol. Microbiol. 53:295-301. 